\title{
Luminescence and scintillation characteristics of YAG:Ce single crystalline films and single crystals
}

\author{
Yu. Zorenko a , J.A. Mares ${ }^{\text {b }}$, P. Prusa ${ }^{\text {b,c }}$, M. Nikl ${ }^{\text {b,* }}$, V. Gorbenko ${ }^{\text {a }}$, V. Savchyn ${ }^{\text {a }}$, R. Kucerkova ${ }^{\text {, }}$, \\ K. Nejezchleb ${ }^{\mathrm{d}}$ \\ ${ }^{a}$ Electronics Department of Ivan Franko National University of Lviv, Gen. Tarnavskogo str., 107, 79017 Lviv, Ukraine \\ ${ }^{\mathrm{b}}$ Institute of Physics AS CR, Cukrovarnicka 10, Prague, Czech Republic \\ ${ }^{\mathrm{C}}$ FNSPE, Czech Technical Universit, Brehova 7, Prague, Czech Republic \\ ${ }^{\mathrm{d}}$ CRYTUR Ltd., Palackeho 175, Turnov, Czech Republic
}

\section{A R T I C L E I N F O}

\section{Article history:}

Received 17 August 2009

Accepted 17 September 2009

\section{Keywords:}

YAG:Ce scintillator

LPE technology

Luminescence

Photoelectron yield

\begin{abstract}
A B S T R A C T
The detailed comparative analysis of luminescent and scintillation properties of the single crystalline films (SCF) of YAG:Ce garnet grown from melt-solutions based on the traditional PbO-based and novel BaO-based fluxes, and of a YAG:Ce bulk single crystal grown from the melt by the Czochralski method, was performed in this work. Using the ${ }^{241} \mathrm{Am}$ ( $\alpha$-particle, $5.49 \mathrm{MeV}$ ) excitation we show that scintillation yield and energy resolution of the optimized YAG:Ce SCF is fully comparable with that of the YAG:Ce single crystal analogue.
\end{abstract}

(c) 2009 Elsevier Ltd. All rights reserved.

\section{Introduction}

$\mathrm{Ce}^{3+}$-doped single crystals (SC) and single crystalline films (SCF) of $\mathrm{Y}_{3} \mathrm{Al}_{5} \mathrm{O}_{12}$ (YAG) and $\mathrm{Lu}_{3} \mathrm{Al}_{5} \mathrm{O}_{12}$ (LuAG) garnets are considered for fast scintillator applications. The YAG:Ce and LuAG:Ce SC are characterized by large (up to 0.2 and 0.6 at.\%, respectively) content of $\mathrm{Y}_{\mathrm{Al}}$ and $\mathrm{Lu}_{\mathrm{Al}}$ antisite defects (AD) (Ashurov et al., 1977). The AD presence is the consequence of high-temperature $\left(\sim 2000^{\circ} \mathrm{C}\right)$ growth of bulk SC of these garnets from melt by the Czochralski or Bridgman methods and energetically favourable creation of such defects (Kuklja, 2000; Stanek et al., 2006). The $\mathrm{Y}_{\mathrm{Al}}$ and $\mathrm{Lu}_{\mathrm{Al}}$ ADs in YAG:Ce and LuAG:Ce SC play the role of emission centers in UV range (Zorenko et al., 2007a) and trapping centers (Nikl et al., 2005). These centers participate in the excitation of the $\mathrm{Ce}^{3+}$ luminescence and are responsible for large amount of slow components in scintillation decay of YAG:Ce and LuAG:Ce SCs (Nikl, 2005; Zorenko et al., 2007b). Due to low temperature of growth by the liquid phase epitaxy (LPE) method, the YAG:Ce and LuAG:Ce SCFs can in principle possess better scintillation properties as compared with the corresponding SC due to the absence of $\mathrm{Y}_{\mathrm{Al}}$ or $\mathrm{Lu}_{\mathrm{Al}}$ ADs. However, the SCF grown from the PbO-based flux are contaminated by lead ions which negatively influence their light yield (LY) and timing characteristics (Babin et al., 2007).

\footnotetext{
* Corresponding author.

E-mail address: nikl@fzu.cz (M. Nikl).
}

Recently, the detailed comparative analysis of scintillation properties of LuAG:Ce SC and SCF was performed (Prusa et al., 2008) and positive influence of the novel BaO-based flux on scintillation characteristics of the Ce-doped YAG and LuAG SCFs was reported (Kucera et al., 2008). In this work, the luminescence and scintillation properties of the YAG:Ce SCF grown by LPE from PbOand $\mathrm{BaO}$-based fluxes and bulk YAG:Ce SC grown by Czochralski method were compared.

\section{Samples and experimental methods}

The YAG:Ce SC was grown in Crytur Ltd (Czech Republic) by Czochralski method from the melt in oxygen-free reduction atmosphere. The YAG:Ce SCF with a thickness of $13-55 \mu \mathrm{m}$ were grown in University of Lviv (Ukraine) by LPE method on YAG substrates from melt-solution (MS) based on $\mathrm{PbO}-\mathrm{B}_{2} \mathrm{O}_{3}$ and $\mathrm{BaO}-$ $\mathrm{B}_{2} \mathrm{O}_{3}-\mathrm{BaF}_{2}$ fluxes (labeled later as YAG: $\mathrm{Ce}(\mathrm{PbO})$ and YAG:Ce $(\mathrm{BaO})$ $\mathrm{SCF}$, respectively) at temperatures within $960-1025^{\circ} \mathrm{C}$. The growth conditions of these SCF are presented in Table 1. A SCF growth rate of $0.48-1.33 \mu \mathrm{m} / \mathrm{min}$ in the case of using the PbO-based flux was significantly larger with respect to that of $0.045-0.075 \mu \mathrm{m} / \mathrm{min}$ in the case of using the BaO-based flux (Table 1).

The Ce content in YAG:Ce SCF was determined using SEM JEOL 6420 equipped by a JXA-8612 MX setup. For the YAG:Ce (PbO) SCF, grown from MS with $\mathrm{CeO}_{2}$ content of 6.2 and 10 mole \%, the $\mathrm{Ce}$ concentration in SCF was 0.032 and 0.073 at.\% (C3 and 42-7 samples, respectively, Table 2). Thus, the segregation coefficient of 
Table 1

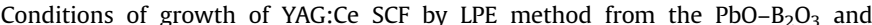
$\mathrm{BaO}-\mathrm{BaF}_{2}-\mathrm{B}_{2} \mathrm{O}_{3}$ fluxes.

\begin{tabular}{lll} 
Molar ratios in melt-solution & $\mathrm{PbO}-\mathrm{B}_{2} \mathrm{O}_{3}$ & $\mathrm{BaO}-\mathrm{BaF}_{2}-\mathrm{B}_{2} \mathrm{O}_{3}$ \\
$\mathrm{BaCO}$ & & $0.4 / 0.4 / 0.2$ \\
$\mathrm{PbO}_{3} / \mathrm{B}_{2} \mathrm{O}_{3}$ & & \\
$R_{2}=\left[\mathrm{Y}_{2} \mathrm{O}_{3}\right] /\left[\mathrm{Al}_{2} \mathrm{O}_{3}\right]$ & 12 & 0.49 \\
$\left.R_{3}=\Sigma \mathrm{R}_{2} \mathrm{O}_{3} / \mathrm{BaCO}_{3}+\mathrm{BaF}_{2}+\mathrm{B}_{2} \mathrm{O}_{3}\right]$ & 0.28 & 0.143 \\
$R_{4}=\left[\mathrm{CeO}_{2}\right] /\left[\Sigma \mathrm{R}_{2} \mathrm{O}_{3}\right]$ & 0.028 & $0.053-0.1$ \\
Temperature of growth, $T_{\mathrm{g}},{ }^{\circ} \mathrm{C}$ & $0.062-0.1$ & $950-1025$ \\
Velocity of substrate rotation $\omega$, rev $/ \mathrm{min}$ & $960-1000$ & 100 \\
SCF growth rate $f_{\mathrm{p}}, \mu \mathrm{m} / \mathrm{min}$ & 100 & $0.045-0.075$ \\
SCF thickness, $\mu \mathrm{m}$ & $0.4-1.5$ & $3.5-9.0$ \\
\hline
\end{tabular}

Ce ions is 0.004-0.007. The Ce concentration in YAG:Ce (BaO) SCFs, grown from MS with $\mathrm{CeO}_{2}$ content of 5.2 mole \% (Ba5 sample) and 10 mol.\% (B10 and B12 samples) was equal or even below of the detecting limit of our apparatus ( $\geq 0.01$ at. \%). Thus, the segregation coefficient of Ce ions in the case of using the BaO-based flux does not exceed the values of $0.001-0.002$ which is in contradiction with the results (Kucera et al., 2008), where higher Ce segregation coefficient was found in both YAG and LuAG SCF grown from BaObased flux. The reason of such a contradictory result is not clear and deserves further studies.

The content of $\mathrm{Ce}$ and $\mathrm{Pb}$ flux dopants in the SCF is also strongly influenced by the growth temperature $T_{\mathrm{g}}$ and increase with decreasing $T_{\mathrm{g}}$ value and vice versa (Kucera et al., 2008). Therefore, we have used relatively high temperatures above $950{ }^{\circ} \mathrm{C}$ (Table 1) for growth of YAG: $\mathrm{Ce}$ (PbO) SCF. The content of Pb ions in such SCF usually appeared below the detection limit of the apparatus, but in some SCF, grown at low temperatures, namely C3 sample, was of about 0.01 at. \%.

The CL spectra were measured at 300 and $80 \mathrm{~K}$ with the setup based on a DMR-4A monochromator and a FEU-106 PMT under the pulsed e-beam $(9 \mathrm{keV}, 100 \mu \mathrm{A})$ excitation (duration of pulse $2 \mu \mathrm{s}$, repetition frequency $3-30 \mathrm{~Hz}$ ). The decay kinetics of the $\mathrm{Ce}^{3+}$ luminescence was measured using the Spectro-fluorometer $199 \mathrm{~S}$ (Edinburgh Instrument) equipped by TBX-04 PMT detection module (IBH Scotland) under excitation by the M-5000 ns coaxial hydrogen-filled flashlamp. The $N_{\text {phels }}$ photoelectron yield was measured using Hybrid DEP PPO 475B PMT under excitation by $\alpha$ particles of ${ }^{241} \mathrm{Am}(5.5 \mathrm{MeV})$ and ${ }^{239} \mathrm{Pu}(5.15 \mathrm{MeV})$ sources with shaping times of $0.5-10 \mu \mathrm{s}$.

\section{Results and discussion}

The CL spectra of YAG:Ce SC and SCF at RT are shown in Fig. 1a. Apart from the intensive $\mathrm{Ce}^{3+}$ luminescence in the $2.75-1.75 \mathrm{eV}$ range with maximum at $2.235 \mathrm{eV}$, the $\mathrm{CL}$ spectra of YAG:Ce SC contain the low-intensity UV emission band arising due to the AD presence (Fig. 1, curve 1). This band in RT range presents a superposition of the luminescence of excitons localized around $\mathrm{Y}_{\mathrm{Al}} \mathrm{AD}$ and the luminescence of $\mathrm{Y}_{\mathrm{Al}} \mathrm{AD}$ in the bands peaked at 4.14 and $3.75 \mathrm{eV}$, respectively. The shape of the latter emission band is

Table 2

Scintillation properties of YAG:Ce SCF in comparison with YAG:Ce SC under excitation by $\alpha$-particles of ${ }^{241} \mathrm{Am}(5.49 \mathrm{MeV}$ eV) source.

\begin{tabular}{lllll}
\hline Samples & $\begin{array}{l}\text { SCF thickness } \\
(\mu \mathrm{m})\end{array}$ & $\begin{array}{l}\text { FWHM } \\
\text { FW(1/5) } \\
(\%)\end{array}$ & $\begin{array}{l}N_{\text {phels }} \text { yield } \\
\text { per MeV } \\
(\text { phels })\end{array}$ & $\begin{array}{l}N_{\text {phels }}(\mathrm{SCF}) \\
\text { to } N_{\text {phel }}(\mathrm{SC})\end{array}$ \\
\hline YAG:Ce (PbO) 42-7 & 58 & $\mathbf{1 1 . 5}(\mathbf{1 5 . 4})$ & 386.8 & $\mathbf{1 1 1 . 1}$ \\
YAG:Ce (PbO) C3 & 55 & $18.5(29.1)$ & 100.3 & 28.8 \\
YAG:Ce (BaO) Ba5 & 2.5 & $15.3(22.9)$ & 202.3 & 58.1 \\
YAG:Ce (BaO) Ba12 & 1.56 & $30.9(42.2)$ & 126.2 & 36.2 \\
YAG:Ce SC & $1 \mathrm{~mm}$ & $\mathbf{1 1}(\mathbf{1 7 . 2})$ & 348.2 & $\mathbf{1 0 0}$ \\
\hline
\end{tabular}
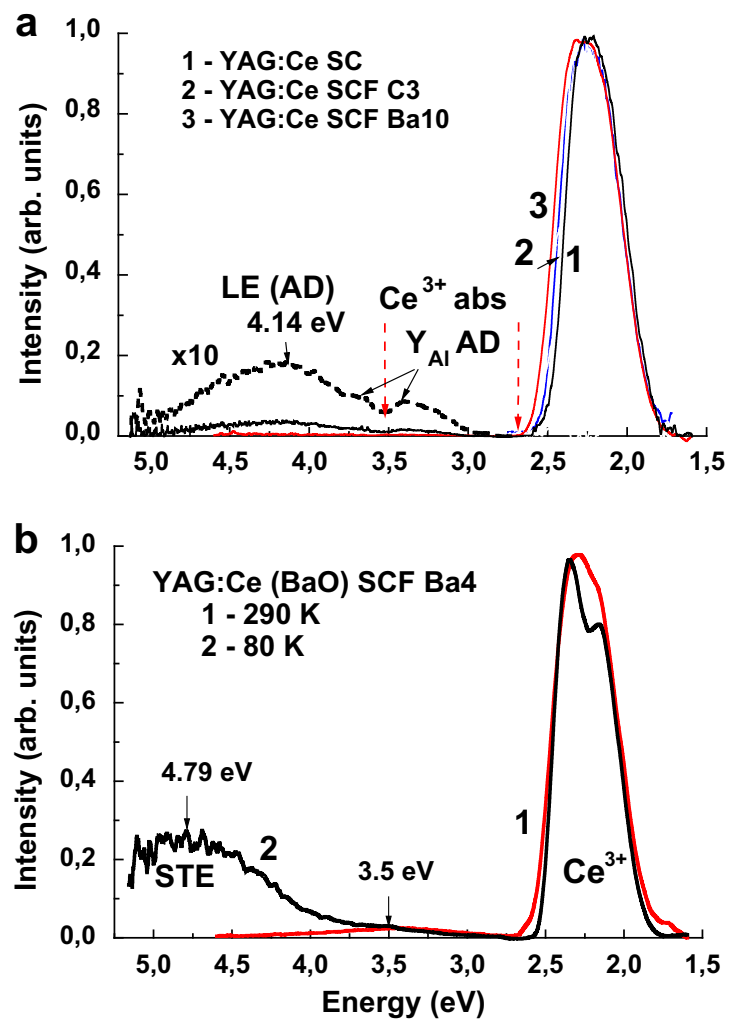

Fig. 1. (a) - CL spectra of YAG:Ce SC (1), YAG:Ce (PbO) (2) and YAG:Ce (BaO) (3) SCF a $300 \mathrm{~K}$. The part of spectra of YAG:Ce SC in the UV range is multiplied by a factor of 10 . Position of the $\mathrm{Ce}^{3+}$ absorption band is marked; (b) - CL spectra of YAG:Ce (BaO) SCF at $80 \mathrm{~K}(1)$ and $300 \mathrm{~K}(2)$.

strongly distorted by the $\mathrm{Ce}^{3+}$ absorption bands peaked at $3.52 \mathrm{eV}$. Opposed to YAG:Ce SC, the emission bands related to $\mathrm{Y}_{\mathrm{Al}} \mathrm{AD}$ are diminished in the CL spectra of YAG:Ce (PbO) and YAG:Ce (BaO) SCFs due to the absence of $\mathrm{Y}_{\mathrm{Al}} \mathrm{AD}$ and only $\mathrm{Ce}^{3+}$ luminescence is observed (Fig. 1, curves 2 and 3). The different positions of the onset of the $\mathrm{Ce}^{3+}$ emission band in CL spectra of YAG:Ce SC and both SCFs (Fig. 1a, curves 1-3) are caused by varying reabsorption of $\mathrm{Ce}^{3+}$ luminescence by the $\mathrm{Ce}^{3+}$ absorption band peaked at $2.69 \mathrm{eV}$.

The CL spectra of YAG:Ce (PbO) and YAG:Ce (BaO) SCF at $80 \mathrm{~K}$ show the emission of self-trapped excitons (STE) in the band peaked at $4.79 \mathrm{eV}$ (Fig. $2 \mathrm{~b}$ ). In CL spectra of YAG:Ce (BaO) SCF the

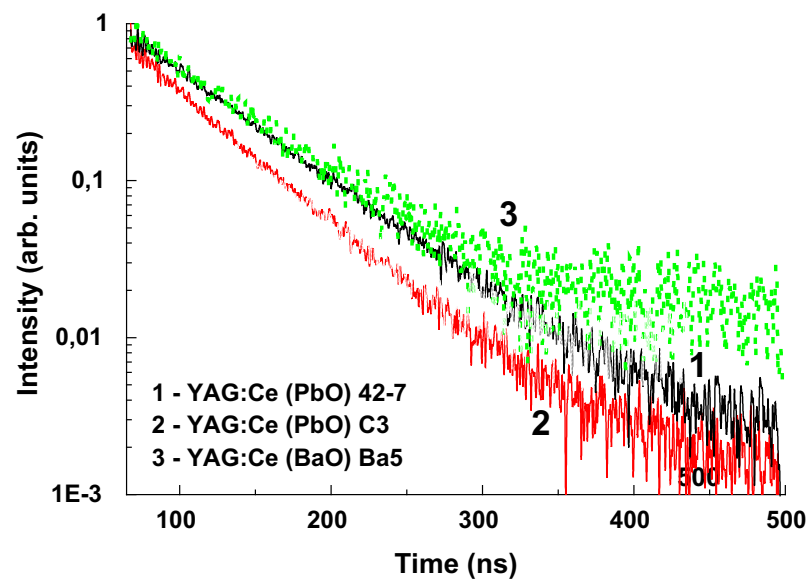

Fig. 2. Decay kinetics of the $\mathrm{Ce}^{3+}$ luminescence in YAG:Ce (PbO) $(1,2)$ and YAG:Ce (BaO) (3) SCF at $530 \mathrm{~nm}$ under excitation at $340 \mathrm{~nm}$ and at RT. 


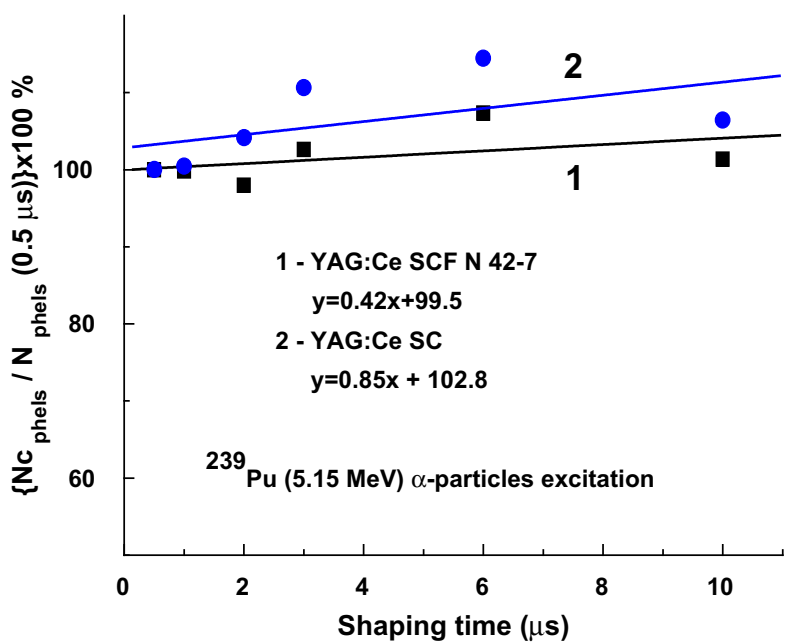

Fig. 3. Dependence of LY of YAG:Ce SCF (1) and YAG:Ce SC (2) on the shaping time of registration of scintillation response under excitation by $\alpha$-particles of $\mathrm{Am}^{241}$ (5.49 MeV) sources.

additional low intensity band peaked at $3.5 \mathrm{eV}$ is present. The origin of this band is not clear and might be connected with the formation of some defects of YAG host during the SCF growth from BaO-based flux.

The decay kinetics of the $\mathrm{Ce}^{3+}$ emission in YAG:Ce (PbO) and YAG: $\mathrm{Ce}(\mathrm{BaO}) \mathrm{SCF}$ under excitation in the $\mathrm{Ce}^{3+}$ absorption band at $340 \mathrm{~nm}$ is shown in Fig. 3. The decay of the $\mathrm{Ce}^{3+}$ emission in YAG:Ce (PbO) SCF with small (below 0.01 at. \%) lead content is a singleexponential with the decay time of $65 \mathrm{~ns}$ which is close to that in YAG:Ce SC. Increasing the lead content in SCF accelerates the decay of the $\mathrm{Ce}^{3+}$ emission in YAG:Ce (PbO) SCF (Fig. 3, curve 3 for C3 sample) which can be caused by the energy transfer from the $\mathrm{Ce}^{3+}$ ions to $\mathrm{Pb}^{2+}$-based complex centers (Babin et al., 2009). The decay of the $\mathrm{Ce}^{3+}$ luminescence in YAG:Ce (BaO) SCF is close to the singleexponential course within one decade but may contain another slower components, the origin of which is not understood and has not been observed in another YAG: $\mathrm{Ce}(\mathrm{BaO})$ SCF samples in (Kucera et al., 2008).

The detailed studies of scintillation response under $\alpha$-particle excitation by ${ }^{241} \mathrm{Am}(5.49 \mathrm{MeV})$ and ${ }^{239} \mathrm{Pu}(5.15 \mathrm{MeV})$ sources showed that $N_{\text {phels }}$ LY of the best YAG:Ce (PbO) SCF (42-7 sample) is even slightly exceeding that of YAG:Ce SC sample (Table 2). Their energy resolutions are similar $(\sim 11 \%)$ under ${ }^{241} \mathrm{Am}(5.49 \mathrm{MeV})$ excitation (Table 2). The increasing lead content in YAG:Ce SCF (C3 sample) leads to the significant $N_{\text {phels }}$ decrease and energy resolution deterioration (Table 2).

The dependence of $N_{\text {phels }}$ on the shaping time of registration of scintillation response of the best YAG:Ce ( $\mathrm{PbO}$ ) SCF (42-7 sample) and reference YAG:Ce SC is shown in Fig. 3. In the latter sample the $N_{\text {phels }}$ LY increases in the $0.5-10 \mu$ s time range by about of $8.5 \%$ while for YAG:Ce SCF this value is at least two time lower ( $4.2 \%)$. The latter observation points to lower content of shallow electron traps in the YAG:Ce SCF with respect to YAG:Ce SC due to absence of the ADs as trapping centers in SCF scintillators (Nikl et al., 2005; Nikl, 2005). Thus, the PbO-based flux can be successfully applied for producing the YAG:Ce SCF scintillators with comparable or even better scintillation properties than those of the SC analogues.

$N_{\text {phels }}$ of the best YAG:Ce (BaO) SCF (B5 sample) achieves the values of about $60 \%$ in comparison with YAG:Ce SC with energy resolution of about $15.3 \%$ (Table 2). The lower values of LY and energy resolution are caused by low ( $\geq 0.01$ at.\%) Ce concentration and small thickness in these SCFs. Considerably better scintillation performance of YAG:Ce (BaO) SCF with higher Ce content were reported very recently (Prusa et al., 2009) though the problem of bad surface morphology and high dislocation density remains unsolved so that there is certainly the room for further BaO-based flux technology optimization.

\section{Conclusions}

Detailed comparison of the luminescent and scintillation properties of the YAG:Ce SCF grown by LPE from the PbO- and $\mathrm{BaO}$-based fluxes and a bulk YAG:Ce SC grown from the melt by Czochralski method, was made. Apart the common $\mathrm{Ce}^{3+}$ luminescence in the visible range, the emission spectra of YAG:Ce SC at RT under high-energy electron excitation show also the complex emission band in UV range arising due to $\mathrm{Y}_{\mathrm{Al}}$ antisite defect presence, which is absent in LPE-grown SCF.

$N_{\text {phels }}$ photoelectron yield of the optimized YAG:Ce SCF, grown from the PbO-based flux, is slightly superior to that of YAG:Ce SC. The energy resolution of these SC and SCF samples is the same $(\sim 11 \%)$ under ${ }^{241} \mathrm{Am}(5.49 \mathrm{MeV}) \alpha$-particle excitation. Therefore, the PbO-based flux can be successfully applied to manufacturing the YAG:Ce SCF scintillators with comparable scintillation figureof-merit with respect to the SC analogues. $N_{\text {phels }}$ of the best YAG:Ce SCF samples, grown from BaO-based flux, is about $60 \%$ of that of YAG:Ce SC, and energy resolution is of about 15.3\%. Inferior performance is presumably caused by too low $\mathrm{Ce}^{3+}$ concentration in these SCF samples. The fundamental problem of the BaO-based flux is also very high viscosity and surface tension as well as rather low SCF growth rate in comparison with the growth from PbObased flux.

\section{Acknowledgments}

This research was supported by Czech Science Foundation (project 202/08/0893) and MES of Ukraine (project SL-28 F).

\section{References}

Ashurov, M., Voronko, Yu., Osiko, V., Solol, A., 1977. Spectroscopic investigation of structural disordering of garnet crystals with rare-earth dopants. Phys. Stat. Sol. (a) $42,101-110$

Babin, V., Gorbenko, V., Makhov, A., Mares, J.A., Nikl, M., Zazubovich, S., Zorenko, Yu, 2007. Luminescence characteristics of $\mathrm{Pb}^{2+}$ centers in undoped and $\mathrm{Ce}^{3 \pm}$ doped Lu3Al5O12 single crystalline films and $\mathrm{Pb}^{2+} \rightarrow \mathrm{Ce}^{3+}$ energy transfer processes. J. Luminescence 127, 384-390.

Babin, V., Bichevin, V., Gorbenko, V., Makhov, A., Mihokova, E., Nikl, M., Vedda, A., Zazubovich, S., Zorenko, Y., 2009. Luminescence of dimer lead centers in aluminium perovskites and garnets. Phys. Stat. Sol. (b) 246, 1318-1326.

Kucera, M., Nitsch, K., Kubová, M., Solovieva, N., Nikl, M., Mares, J.A., 2008. Ce-doped YAG and LuAG epitaxial films for scintillation detectors. IEEE Trans. Nucl. Sci. 55, 1201-1205.

Kuklja, M.M., 2000. Defects in yttrium aluminium perovskite and garnet crystals: atomistic study. J. Phys. Condens. Matter. 12, 2953-2967.

Nikl, M., Mihokova, E., Pejchal, J., Vedda, A., Zorenko, Yu, 2005. The antisite LuAl defect-related trap in Lu3A15012:Ce single crystal. Phys. Stat. Sol. (b) 242, R119-R121.

Nikl, M., 2005. Energy transfer phenomena in the luminescence of wide band-gap scintillators. Phys. Stat. Sol. (a) 202, 201-206.

Prusa, P., Cechak, T., Mares, J.A., Nikl, M., Zorenko, Y., Gorbenko, V., Tous, J., Blazek, K., 2008. The $\alpha$-particle excited scintillation response of the liquid phase epitaxy grown LuAG: Ce thin films. Appl. Phys. Lett. 92, 041903.

Prusa, P., Nikl, M., Mares, J.A., Kucera, M., Nitsch, K., Beitlerova, A., 2009. The $\alpha-$ particle excited scintillation response of YAG: Ce thin films grown by liquid phase epitaxy. Phys. Stat. Sol. (a) 206, 1494-1500.

Stanek, C.R., McClellan, K.J., Levy, M.R., Grimes, R.W., 2006. Extrinsic defect structure of RE3Al5012 garnets. Phys. Stat. Sol. (b) 243, R75-R77.

Zorenko, Yu., Voloshinovskii, A., Savchyn, V., Vozniak, T., Nikl, M., Nejezchleb, K., Mikhailin, V., Kolobanov, V., Spassky, D., 2007a. Exciton and antisite defectrelated luminescence in Lu3Al5O12 and Y3Al5O12 garnets. Phys. Stat. Sol. (b) 244, 2180-2189.

Zorenko, Y., Gorbenko, V., Konstankevych, I., Voznjak, T., Savchyn, V., Nikl, M., Mares, J.A., Nejezchleb, K., Mikhailin, V., Kolobanov, V., Spassky, D., 2007b. Single crystalline film scintillators based on Ce- and Pr-doped aluminium garnets. Radiat. Meas. 42, 528-532. 